\title{
Comparison of Decontamination Efficacy between the Rapid Hygrothermal Pasteurization and Sodium Hypochlorite Treatments
}

\author{
Dusida Tirawat $^{1}$, Hiromizu Kunimoto ${ }^{1}$, Seiji Noma ${ }^{2 *}$, Noriyuki Igura ${ }^{2}$, Mitsuya Shimoda ${ }^{2}$ \\ ${ }^{1}$ Laboratory of Food Process Engineering, Division of Food Biotechnology, Department of Bioscience \& Biotechnology, Graduate \\ School of Bioresources and Bioenvironmental Sciences, Kyushu University, Fukuoka, Japan; ${ }^{2}$ Laboratory of Food Process Engi- \\ neering, Division of Food Biotechnology, Department of Bioscience \& Biotechnology, School of Agriculture, Kyushu University, \\ Fukuoka, Japan. \\ Email: *nomas@agr.kyushu-u.ac.jp
}

Received April $2^{\text {nd }}, 2013$; revised May $5^{\text {th }}, 2013$; accepted May $13^{\text {th }}, 2013$

Copyright (C) 2013 Dusida Tirawat et al. This is an open access article distributed under the Creative Commons Attribution License, which permits unrestricted use, distribution, and reproduction in any medium, provided the original work is properly cited.

\begin{abstract}
We developed a novel rapid hygrothermal pasteurization (RHP) method using saturated water vapor with a dew point of $100^{\circ} \mathrm{C}$. The aim of this paper is to compare the effect of RHP treatment versus conventional sodium hypochlorite (Na$\mathrm{ClO}$ ) treatments on inactivation of natural mesophilic bacteria and quality attributes on fruits and vegetables. The RHP treatment was performed within a second by free-falling samples (cabbage, cucumber, carrot, bell pepper, pineapple and melon) through cylindrical processing chamber filled with steam. $\mathrm{NaClO}$ treatment was performed by washing samples with $\mathrm{NaClO}$ solution $(100 \mathrm{mg} / \mathrm{mL}$ of free chlorine $(\mathrm{pH} 7)$, for $1 \mathrm{~min})$. The RHP treatment showed a significantly higher inactivation effect than $\mathrm{NaClO}$ treatment on all tested samples. The RHP treatment had a slightly larger influence on color and vitamin $\mathrm{C}$ content than $\mathrm{NaClO}$ treatment in cabbage. Furthermore, the effects of treatment time and operated temperature were also determined using microbial model system. Elongation of treatment time did not significantly increase the microbial inactivation effect. Lowering of operated temperature by mixing air into steam tended to decrease the inactivation effect. From these results, RHP treatment could be used as an alternative method for decontaminating microorganisms on fruits and vegetables, except on leafy vegetable. In addition, it is suggested that microbial inactivation by RHP treatment was achieved through the initial condensation stage of water vapor on sample surface. By contrast, interfusion of air disturbed the effective condensation of water vapor.
\end{abstract}

Keywords: Rapid Hygrothermal Pasteurization; Sodium Hypochlorite; Fresh-Cut Fruits; Vegetables

\section{Introduction}

In recent years, consumption of fresh-cut fruits and vegetables has continuously increased. However, fruits and vegetables are contaminated by microorganisms on their surfaces from many sources, such as soil, water, wild animals, birds, and insects during the growing stage. Processes involving harvesting, washing, cutting, packaging, and shipping could create additional contamination. In addition, a large area of cut surfaces can provide ideal conditions for growth of microorganisms, including foodborne pathogens and spoilage microorganisms [1]. Microorganisms impact the economic value of fresh-cut products by decreasing product shelf-life, through spoilage, and by posing a risk to public health by causing

"Corresponding author. foodborne disease [2].

Chlorine solution prepared from sodium hypochlorite $(\mathrm{NaClO}, 50-200 \mathrm{mg} / \mathrm{L})$ is the most used sanitizing agent for washing fresh produce, because it is cheap, easily applied, chemically stable, readily available, and has been authorized for use with food by FDA and Japanese Ministry of health, Labor and Welfare [3-5]. However, it is known that sodium hypochlorite induces formation of harmful carcinogenic chlorinated by-products such as chloramines and trihalomethanes.

We have developed a rapid hygrothermal pasteurization (RHP) method using saturated water vapor with a dew point of $100^{\circ} \mathrm{C}$ as a novel pasteurization method for fresh produces. The RHP had the potential to reduce number of mesophilic bacteria with retaining a nutriational component ascorbic acid, and preserving quality 
attributes such as color and firmness in many kinds of fresh-cut fruits and vegetables [6]. In addition, the RHP treatment showed greater or equal decontamination effect compared to $\mathrm{NaClO}$ solution against naturally contaminated mesophilic bacteria, coliform bacteria, lactic acid bacteria and yeast on Chinese cabbage [7]. However, practical use of the RHP treatment requires the investigation of the effect of the RHP treatment on microbial inactivation efficacy and quality changes in various fresh produce with comparing to the conventional method, $\mathrm{NaClO}$ solution treatments.

On the other hand, to obtain high inactivation effect of RHP treatment with minimal quality change to fresh produces, the clarification of its inactivation behaviors of the RHP treatment is required. However, in our previous studies, the effects of treatment time and operated temperature on inactivation effect in RHP treatment remain obscure.

The aim of this study is to compare the inactivation efficacy of RHP and the conventional method, washing with $\mathrm{NaClO}$ solution, on reduction of indigenous aerobic mesophilic bacteria and quality changes of ready-to-use fruits and vegetables. The effects of treatment time and operated temperature in RHP treatment on inactivation of Escherichia coli were also determined using microbial model system.

\section{Materials and Methods}

\subsection{Sample Preparation}

\subsubsection{Fresh Sample}

Six most commonly used for ready-to-use fruits and vegetables were chosen. Cabbage (Brassica oleraceae L.), cucumber (Cucumis sativus L.), carrot (Daucus carota L.), bell pepper (Capsicum annuum L.), pineapple (Ananas comosus L.), and melon (Cucumis melo L.) were purchased from local markets and stored at $4^{\circ} \mathrm{C}$ until the experiments. They were cut with a sharp stainless steel knife to the size shown in Table 1. The experiments were carried out during September to October 2011. For quality attributes measurement, the samples in the assigned bag (approximately 10 - 12 samples) were randomly cho-

Table 1. Sample preparation of fruits and vegetables.

\begin{tabular}{clc}
\hline Sample & Part & Size \\
\hline Cabbage & Leaf & $2 \mathrm{~cm} \times 3 \mathrm{~cm}$ \\
Carrot & Root & Slice in round (thickness $0.3 \mathrm{~cm})$ \\
Cucumber & Fruit & Slice in round (thickness $0.3 \mathrm{~cm})$ \\
Bell pepper & Fruit & $1 \mathrm{~cm} \times 4 \mathrm{~cm}$ \\
Pineapple & Fruit & $3 \mathrm{~cm} \times 4 \mathrm{~cm} \times 1 \mathrm{~cm}$ \\
Melon & Fruit & $3 \mathrm{~cm} \times 4 \mathrm{~cm} \times 1.5 \mathrm{~cm}$ \\
\hline
\end{tabular}

sen to minimize error due to the product variability.

\subsubsection{Microbial Model System}

Escherichia coli NBRC 3301 was purchased from the Biological Resource Center, National Institute of Technology and Evaluation (Chiba, Japan). E. coli cells were inoculated on tryptic soy agar slants (TSA; Difco, Sparks, $\mathrm{MD}$, USA) and incubated at $30^{\circ} \mathrm{C}$ for $24 \mathrm{~h}$. One day prior to experiment, $E$. coli cells on the slant individually subcultured by two consecutive transfers to $6 \mathrm{~mL}$ of tryptic soy broth (TSB; Difco) and incubated at $30^{\circ} \mathrm{C}$ for $16 \mathrm{~h}$. $E$. coli cells were then washed three times in $5 \mathrm{~mL}$ of $0.85 \%$ $(\mathrm{w} / \mathrm{v})$ sodium chloride solution (Nacalai Tesque, Inc., Kyoto, Japan) by centrifugation at $2000 \times \mathrm{g}$, and $4^{\circ} \mathrm{C}$ for $10 \mathrm{~min}$. Obtained cell pellets were re-suspended in $2 \mathrm{~mL}$ of $0.85 \%(\mathrm{w} / \mathrm{v})$ sodium chloride solution to attain the final cell density of about $10^{10} \mathrm{CFU} / \mathrm{mL}$.

High-quality polyvinylidene difluoride (PVDF) membrane (GE Healthcare UK Limited, Buckinghamshire, UK) was pre-wet in $70 \%$ ethanol for 15 min followed by washing in distilled water for $30 \mathrm{~min}$. After the membrane was dried, 501 of $E$. coli cell suspension $\left(10^{8} \mathrm{CFU} /\right.$ $\mathrm{mL}$ ) was spotted on the membrane and stood in clean bench for drying. The membrane was cut into an oversized square shape, and taped on a styrene foam board. This was used as a microbial model system.

\subsection{Rapid Hygrothermal Pasteurization Treatment}

A RHP apparatus was shown in a previous study [6]. Pasteurization trial was performed after the air was completely excluded from the chamber with steam, which was confirmed by reaching the dew point to $100^{\circ} \mathrm{C}$. Since the steam in chamber is in communication with the air, samples can be dropped by free-falling through the steam chamber. The time needed to pass through the chamber, treatment time, was $0.3 \mathrm{~s}-0.4 \mathrm{~s}$. Treated samples were received by mesh tray for avoiding bruises.

For the investigation of the effect of treatment time on inactivation using microbial model system, the model was hanged from a string connected to a belt conveyor. The treatment time, the time to pass through the cylindrical steam chamber, was changed by modulated the speed of the belt conveyor. For the investigation of the effect of treatment temperature on inactivation, the temperature of cylindrical steam chamber was lowered by entrapped air into the steam.

\subsection{Sodium Hypochlorite (NaClO) Treatment}

Chlorinated water was prepared by adding sodium hypochlorite solution to distilled water to obtain $100 \mathrm{mg} / \mathrm{L}$ free chlorine solution. The $\mathrm{pH}$ of sodium hypochlorite 
solution was adjusted to $7.0 \pm 0.5$ using hydrochloric acid $[8,9]$. Cut samples were washed in different glass container with approximately $100 \mathrm{~g} / \mathrm{L}$ of product in Na$\mathrm{ClO}$ solution for $1 \mathrm{~min}$ with agitation. After that the excess $\mathrm{NaClO}$ solution was eliminated by a manually operated spinner for $1 \mathrm{~min}$. The samples were then subjected to microbial analysis and quality attributes measurement.

\subsection{Microbial Analysis}

\subsubsection{Fresh Cut Produce}

Each fruit and vegetable sample $(10 \mathrm{~g})$ was added with $90 \mathrm{~mL}$ of sterile $0.1 \%$ peptone water in stomacher bags (Eiken kizai Co., Ltd., Tokyo, Japan) and then homogenized with a stomacher (IUL Instrument, Barcelona, Spain) for $90 \mathrm{~s}$, and serially diluted. The diluted samples of $0.1 \mathrm{~mL}$ were plated onto tryptic soy agar (TSA, Difco, Sparks, MD, USA) and incubated for $24 \mathrm{~h}$ at $30^{\circ} \mathrm{C}$ for determining mesophilic bacteria. Viable cells were enumerated as colony forming unit per gram of sample $(\mathrm{CFU} / \mathrm{g})$.

\subsubsection{Microbial Model System}

The membrane was removed from the styrene foam board and the part of only inoculated circular site was cut off by sterile scissors. Inoculated circular site was put in a 15 $\mathrm{mL}$ centrifuge tube with $2 \mathrm{~mL}$ of $0.85 \%(\mathrm{w} / \mathrm{v})$ sodium chloride solution vortexed for 3 min vigorously. Appropriate serial dilutions were prepared by using $0.85 \%(\mathrm{w} / \mathrm{v})$ sodium chloride solution, which was after each model treatment, and the solution was plated onto TSA. Total viable count of $E$. coli was defined as the colony number formed after incubation at $30^{\circ} \mathrm{C}$ for $24 \mathrm{~h}$.

\subsection{Quality Attributes}

\subsubsection{Surface Color}

The surface color change of the samples were assessed by taking $10-12$ measurements of $L^{*}$ (lightness-darkness), a* (redness-greenness), and $b^{*}$ (yellowness-blueness) indices of the CIE LAB colorimetric system by use of a CR-100 chromameter (Minolta, Osaka, Japan) within $2 \mathrm{~h}$ after each treatment. The instrument was previously calibrated using white $\left(L^{*}=94.0, a^{*}=-2.7\right.$, and $b^{*}$ $=1.0)$ standards. Three points of the equatorial region of each sample were selected. Before and after treatment, the same areas were analyzed in triplicate.

\subsubsection{Ascorbic Acid Content}

Ascorbic acid content in each sample was determined by a method described previously [10] with slight modification. Replicates of $10 \mathrm{~g}$ of samples were weighed, homogenized with $20 \mathrm{~mL}$ cold $2 \%$ metaphosphoric acid, then filtered through filter paper No. 2 (Advantec, Toyo Roshi Kaisha, Ltd.). The exudate was immediately used for the determination of the ascorbic acid content using a reflection photometer (Merck, RQflex, Germany). The ascorbic acid contents were expressed in $\mathrm{mg} / 100 \mathrm{~g}$.

\subsection{Statistical Analysis}

Data presented were mean values of replicated experiments. Significant difference among untreated sample, RHP treatment and $\mathrm{NaClO}$ treatment was determined by Tukey's method at 5\% level of significance using Ekuseru-Toukei 2006 (Social Survey Research Information Co., Ltd., Japan).

\section{Results and Discussion}

We have reported that the RHP treatment can reduce microorganisms on the surface of fresh fruits and vegetables surfaces with retaining a nutritional component and preserving quality attributes [6]. This series of experiments were performed during September to December 2008. The microbial flora and the heat resistance of the microorganisms on naturally contaminated fresh produce may vary depending on season. Therefore, the effect of RHP treatment on inactivation of microorganisms and quality of fresh fruits and vegetables was investigated again at the same season with $\mathrm{NaClO}$ treatment.

\subsection{Microbial Analysis}

Figure 1 shows the viable count in each sample before and after $\mathrm{NaClO}$ treatment or RHP treatment. The reduction in viable count was significantly higher in RHP treatment than in $\mathrm{NaClO}$ treatment for all kinds of sample tested. $\mathrm{NaClO}$ treatment reduced the count by $0.2-1.4$ $\log$, while RHP treatment reduced it by $1-2.5 \log$. Efficacy of $\mathrm{NaClO}$ solution treatment agreed with previous reports that indicated the efficacy of chlorine-based sanitizers on fresh-cut produce with a reduction of $1-2 \log$ orders [9,11-17]. Soliva-Fortuny and Martin-belloso (2003), described that chlorine only delays microbial spoilage and does not exhibit any beneficial effects in biochemical and physiological disorders of fresh produce [18]. It was reported that chlorine dips should not be relied on to kill pathogens on produce but they should be used to reduce viable microorganisms [14].

\subsection{Quality Attributes}

\subsubsection{Surface Color Changes}

Surface color of fresh-cut fruits and vegetables was evaluated through $\mathrm{L}^{*}, \mathrm{a}^{*}$, and $\mathrm{b}^{*}$ values. Color difference $(\Delta \mathrm{E})$ was calculated by values of $\mathrm{L}^{*}, \mathrm{a}^{*}$, and $\mathrm{b}^{*}$. The colorimeter analyses showed no significant changes in term of $\mathrm{L}^{*}, \mathrm{a}^{*}$, and $\mathrm{b}^{*}$ in all kinds of samples after Na$\mathrm{ClO}$ treatment (Table 2). Meanwhile, after RHP treatment, significant changes in $L^{*}, a^{*}$, and $b^{*}$ values were 


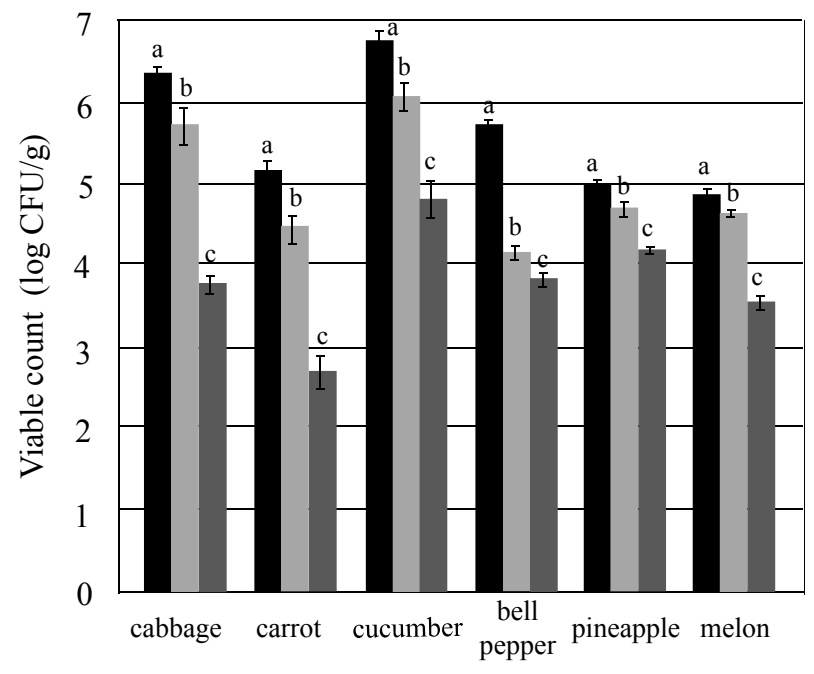

Figure 1. Viable count of mesophilic bacteria on each sample before and after $\mathrm{NaClO}(100 \mathrm{mg} / \mathrm{L}$ free chlorine, $1 \mathrm{~min})$ or RHP treatment $\left(100^{\circ} \mathrm{C}, 0.3 \mathrm{sec}\right)$. Black, gray and dark gray columns show untreated, NaClO treatment and RHP treatment, respectively. Data represent mean \pm standard deviation of replicated experiments $(n=9)$. Means within the same group with different letters are significantly different $(p<0.05)$.

not observed in carrot, cucumber, bell pepper, pineapple, and melon. Therefore, it is shown that RHP treatment does not affect color of these fresh produces as with Na$\mathrm{ClO}$ treatment.

However, noticeable change in $\mathrm{a}^{*}$ and $\mathrm{b}^{*}$ value was observed in cabbage after RHP treatment. A decreasing $\mathrm{a}^{*}$ value indicates a heightening of the green color. The RHP treated cabbage showed a greener color than $\mathrm{NaClO}$ and control. The effects of heat treatments on the color of green vegetables were attributed to air removal around the fine hairs on the surface of plant tissues and to the expulsion of air between cells. In the initial stage of heating, an increase in green color was observed in many kinds of vegetables such as green beans and asparagus [19]. An increase in $b^{*}$ value points an increase in yellow color. Yellowing is considered the major effect of chlorophyll degradation [20]. Chlorophyll deterioration is strongly associated with lipoxygenase activity and concomitant fatty acid degradation [21]. This pathway might be occurred when heat was transferred to the inner layer and degraded chlorophyll. In previous study, we observed that the RHP treatment reduced about $50 \%$ of chlorophyll content in cabbage [6].

\subsubsection{Ascorbic Acid Content}

Figure 2 shows ascorbic acid content in fresh-cut fruits and vegetables. A significant decrease in ascorbic acid content was found after both $\mathrm{NaClO}$ and RHP treatments

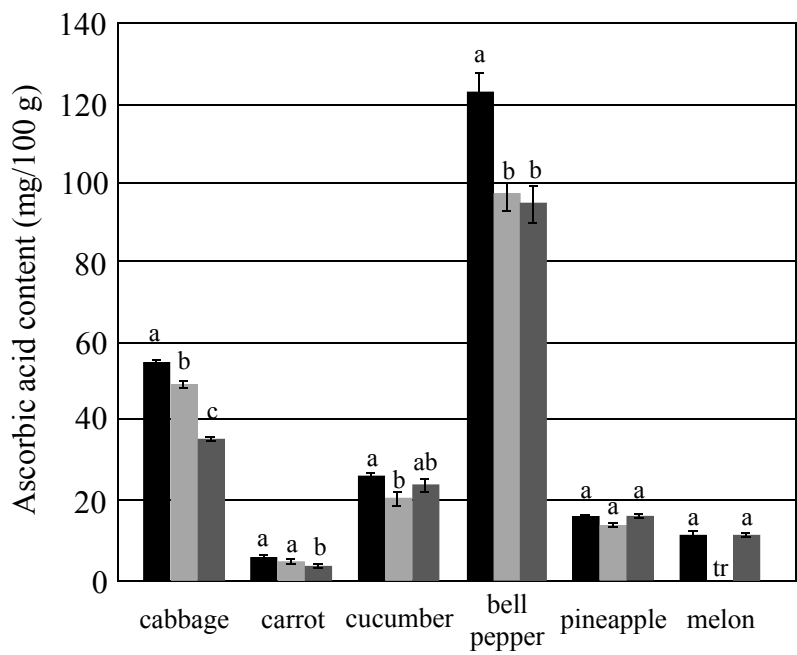

Figure 2. Ascorbic acid content (mg/100 g) on each sample before and after $\mathrm{NaClO}(100 \mathrm{mg} / \mathrm{L}$ free chlorine, $1 \mathrm{~min})$ or RHP treatment $\left(100^{\circ} \mathrm{C}, 0.3 \mathrm{sec}\right)$. Black, gray and dark gray columns show untreated, NaClO treatment and RHP treatment, respectively. Data represent mean \pm standard deviation of replicated experiments $(n=12)$. Means within the same group with different letters are significantly different (p < 0.05). "tr" stands for "trace".

in cabbage, and the decreasing level was larger in RHP treatment than $\mathrm{NaClO}$ treatment. In the case of cabbage, ascorbic acid content was significantly lower after RHP treatment compared to that after $\mathrm{NaClO}$ treatment. In leafy vegetables like lettuce, a similar result was also reported that ascorbic acid content in chlorine treated lettuce was higher than in steam treated one [8]. In carrot, $\mathrm{NaClO}$ did not reduce the content, whereas RHP treatment significantly decreased it. In cucumber, noticeable reduction in the content was not observed after both treatments. In bell pepper, $\mathrm{NaClO}$ and $\mathrm{RHP}$ treatment similarly reduced the ascorbic acid content. Both $\mathrm{NaClO}$ solution and RHP treatments caused no change in ascorbic acid content in pineapple. In melon, $\mathrm{NaClO}$ treatment reduced the content to trace level.

Ascorbic acid is a labile molecule that could be easily degraded. Processing induced losses of ascorbic acid depending on the degree of heating, leaching into the cooking medium, surface area exposed to water and oxygen, $\mathrm{pH}$, presence of transition metals, and any other factors that facilitate oxidation [22]. Sungpuag et al. (1999) observed that losses of ascorbic acid were associated with a content of processing water [23]. Meanwhile, some study indicated that thermal treatment can retain ascorbic acid content higher than non-thermal treatment [24]. Also in our study, RHP treated sample also had higher ascorbic acid content than $\mathrm{NaClO}$-treated one in some kinds of fresh-cut fruits and vegetables. 
Table 2. $\mathrm{L}^{*}, \mathrm{a}^{*}$ and $\mathrm{b}^{*}$ values on each sample after $\mathrm{NaClO}$ treatment $(100 \mathrm{mg} / \mathrm{L}$ free chlorine, $1 \mathrm{~min})$ or $\mathrm{RHP}$ treatment $\left(100^{\circ} \mathrm{C}\right.$, $0.3 \mathrm{sec}$ ).

\begin{tabular}{|c|c|c|c|c|c|c|c|c|}
\hline & \multirow{2}{*}{ Sample } & \multicolumn{2}{|c|}{$\mathrm{L}^{*}$} & \multicolumn{2}{|c|}{$a^{*}$} & \multicolumn{2}{|c|}{$\mathrm{b}^{*}$} & \multirow{2}{*}{$\Delta \mathrm{E}$} \\
\hline & & Untreated & Treated & Untreated & Treated & Untreated & Treated & \\
\hline \multirow{6}{*}{$\mathrm{NaClO}$} & Cabbage & 81.74 & 81.92 & -10.62 & -10.57 & 18.10 & 18.09 & 0.186 \\
\hline & Carrot & 61.14 & 61.16 & 21.27 & 20.91 & 49.10 & 47.36 & 1.780 \\
\hline & Cucumber & 66.64 & 66.18 & -8.98 & -8.71 & 16.01 & 16.16 & 0.547 \\
\hline & Bell pepper & 54.00 & 54.46 & -0.40 & -0.53 & 34.26 & 34.59 & 0.588 \\
\hline & Pineapple & 63.55 & 62.88 & -5.16 & -5.11 & 30.84 & 31.12 & 0.730 \\
\hline & Melon & 62.26 & 61.91 & -11.10 & -11.01 & 23.01 & 22.78 & 0.436 \\
\hline \multirow{6}{*}{ RHP } & Cabbage & 82.57 & 80.91 & -13.11 & $-18.46^{\#}$ & 23.77 & $28.40^{\#}$ & 7.264 \\
\hline & Carrot & 66.93 & 65.06 & 16.54 & 16.38 & 34.34 & 34.71 & 1.920 \\
\hline & Cucumber & 70.03 & 69.14 & -9.83 & -9.59 & 17.88 & 17.88 & 0.919 \\
\hline & Bell pepper & 55.98 & 55.46 & -0.50 & -0.28 & 35.51 & 35.04 & 0.738 \\
\hline & Pineapple & 94.09 & 63.17 & -5.78 & -5.85 & 33.78 & 33.76 & 0.923 \\
\hline & Melon & 62.66 & 62.78 & -7.27 & -7.33 & 20.64 & 20.21 & 0.458 \\
\hline
\end{tabular}

Symbols “\#” represent significant difference between untreated and treated samples at $\mathrm{p}<0.05$.

\subsection{Analysis of Inactivation Behavior Using Microbial Model System}

In a previous study, it was shown that RHP treatment had inactivation effect of $0.7-2 \log$ orders [8]. However, the experimental conditions including treatment time and operated temperature were limited to $0.3 \mathrm{sec}$ and $100^{\circ} \mathrm{C}$. Then, effects of treatment time and operated temperature on inactivation were investigated. For this purpose, a microbial model system, PVDF membrane with $E$. coli cells was applied. Due to inactivation effect on fresh produce generally varies by site of the produce, and, moreover, many sample number is needed for obtaining faithful data.

Figure 3(a) shows the effect of treatment time on inactivation of $E$. coli cells on microbial model system. The treatment temperature was set at $100^{\circ} \mathrm{C}$. The treatment time for $0.3 \mathrm{sec}$ inactivated $E$. coli cells by $3.4 \mathrm{log}$ order, and the increase in treatment time tended to enhance the inactivation effect. However, the increase in inactivation effect was not significant. Applying saturated water vapor at $100^{\circ} \mathrm{C}$ leads to an immediate condensation on the surfaces of solid foods [8]. It is considered that inactivation by the RHP treatment was achieved during the initial phase condensation of water vapor on the sample surface, and the resultant water layer suppressed the heat conduction mediated by the additional condensation of water vapor.

Figure 3(b) shows the effect of treatment temperature on inactivation of $E$. coli cells on microbial model system. The largest inactivation ratio of $3.2 \mathrm{log}$ order was observed at $100^{\circ} \mathrm{C}$ and $96^{\circ} \mathrm{C}$. The inactivation ratio de- creased when the treatment temperature was lowered, and inactivation ratio at $80^{\circ} \mathrm{C}$ was $2.6 \mathrm{log}$ order. These results suggest that RHP treatment is more effective in the air-absent steam condition than in the air-present steam condition, meaning that saturation of treatment chamber by water vapor is important for the effective condensation of water vapor on the sample surface for avoiding interference by air barriers around treating samples.

\section{Summary}

Chlorine compounds are usually used as fresh cut sanitizers at levels of $50-200 \mathrm{mg} / \mathrm{l}$ free chlorine and with typical contact times of less than 5 min $[25,26]$. In Japan, sodium hypochlorite solution $(100-200 \mathrm{mg} / \mathrm{l}$ of free chlorine) has been authorized for use with food [27]. However, in some European countries including Germany, the Netherlands, Switzerland and Belgium, the use of chlorine in fresh-cut products is prohibited due to consumer health concern [28]. The novel method, RHP treatment without using chemicals, indicated a similar or higher level of microorganism inactivation effect on many kinds of fresh-cut produces when compared with conventional method, $\mathrm{NaClO}$ treatment. This suggests that RHP treatment can be an alternative method to conventional $\mathrm{NaClO}$ solution treatment, for fresh-cut fruits and vegetables with the exception of leafy vegetables. Examination using the microbial model system revealed that RHP treatment was most effective at $100^{\circ} \mathrm{C}$ for 0.3 sec for obtaining high inactivation effect with keeping quality of foods. The RHP treatment has advantage to avoid the use of chemicals such as sodium hypochlorite 


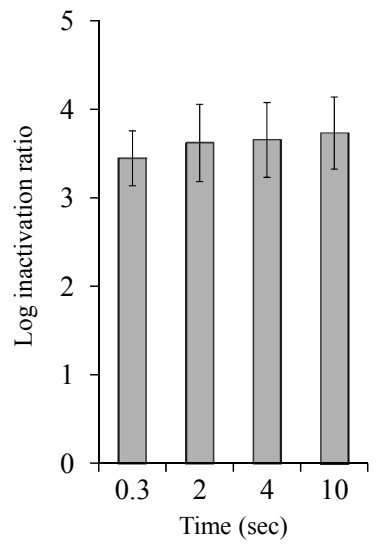

(a)

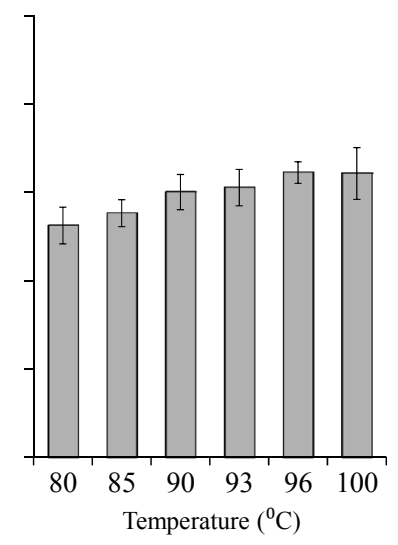

(b)

Figure 3. Effect of time (a) and temperature (b) on inactivation ratio of $E$. coli on PVDF membrane model. Treatment temperature and time was set at $100^{\circ} \mathrm{C} \mathrm{(a)} \mathrm{and} 0.3 \mathrm{sec}(\mathrm{b})$, respectively. Data represent mean \pm standard deviation of replicated experiments. Inactivation ratio was calculated by the following equation; Inactivation ratio $=N_{0} / N$, where $N_{0}$ and $N$ show colony count before and after RHP treatment, respectively.

that associated with formation of carcinogenic chlorine compounds in washing water.

\section{REFERENCES}

[1] R. Trias, L. Bañeras, E. Badosa and E. Montesinos, "Bioprotection of Golden Delicious Apples and Iceberg Lettuce against Foodborne Bacterial Pathogens by Lactic Acid Bacteria," International Journal of Food Microbiology, Vol. 123, No. 1-2, 2008, pp. 50-60. doi:10.1016/i.ijfoodmicro.2007.11.065

[2] C. Nguyen-the and F. Carlin, "The Microbiology of Minimally Processed Fresh Fruits and Vegetables," Critical Reviews in Food Science and Nutrition, Vol. 34, No. 4, 1994, pp. 371-401. doi:10.1080/10408399409527668

[3] S. Fukuzaki, H. Urano and S. Yamada, "Effect of pH on the Efficacy of Sodium Hypochlorite Solution as Cleaning and Bactericidal Agents," Journal of the Surface Fin- ishing Society of Japan, Vol. 58, No. 8, 2007, pp. 465469. doi:10.4139/sfj.58.465

[4] L. A. Keskinen, A. Burke and B. A. Annous, "Efficacy of Chlorine, Acidic Electrolyzed Water and Aqueous Chlorine Dioxide Solutions to Decontaminate Escherichia coli O157:H7 from Lettuce Leaves," International Journal of Food Microbiology, Vol. 132, No. 2-3, 2009, pp. 134140.

[5] A. Issa-Zacharia, Y. Kamitani, N. Miwa, H. Muhimbula and K. Iwasaki, "Application of Slightly Acidic Electrolyzed Water as a Potential Non-thermal Food Sanitizer for Decontamination of Fresh Resdy-to-eat Vegetables and Sprouts," Food Control, Vol. 22, No. 3-4, 2011, pp. 601-607. doi:10.1016/j.foodcont.2010.10.011

[6] D. Tirawat, A. Meno, H. Fujiwara, K. Higo, S. Noma, N. Igura and M. Shimoda, "Development of Rapid Hygrothermal Pasteurization using Saturated Water Vapor," Innovative Food Science and Emerging Technologies, Vol. 11, No. 3, 2010, pp. 458-463.

doi:10.1016/j.ifset.2010.01.015

[7] D. Tirawat, S. Noma, H. Kunimoto, S. Tameda, E. Nishibayashi, N. Igura and M. Shimoda, "Decrease in the Number of Microbial Cells on Chinese cabbage by Rapid Hygrothermal Pasteurization using Saturated Water Vapor," International Food Research Journal, Vol. 20, No. 2, 2013, pp. 981-985.

[8] A. B. Martín-Diana, D. Rico, C. Barry-Ryan, J. M. Frías, G. T. M. Henehan, J. M. Barat, "Efficacy of Steamer JetInjection as Alternative to Chlorine in Fresh-Cut Lettuce," Postharvest Biology and Technology, Vol. 45, No. 1, 2007, pp. 97-107. doi:10.1016/j.postharvbio.2007.01.013

[9] F. López-Gálvez, A. Allende, P. Truchado, A. MartínezSánchez, J. Tudela, M. Selma and M. Gil, "Suitability of Aqueous Chlorine Dioxide versus Sodium Hypochlorite as an Effective Sanitizer for Preserving Quality of FreshCut Lettuce while Avoiding By-product Formation," PostHarvest Biology and Technology, Vol. 55, No. 1, 2010, pp. 53-60. doi:10.1016/j.postharvbio.2009.08.001

[10] S. Koide and J. Shi, "Microbial and Quality Evaluation of Green Peppers Stored in Biodegradable Film Packaging," Food Control, Vol. 18, No. 9, 2007, pp. 1121-1125. doi:10.1016/i.foodcont.2006.07.013

[11] M. Y. Akbas and H. Olmez, "Inactivation of Escherichia coli and Listeria monocytogenes on Iceberg Lettuce by Dip Wash Treatments with Organic Acids," Letters in Applied Microbiology, Vol. 44, No. 6, 2007, pp. 619-624. doi:10.1111/j.1472-765X.2007.02127.x

[12] S. Ruiz-Cruz, E. Acedo-Felix, M. Diaz-Cindo, M. A. Islas-Osuna and G. A. Gonzalez-Aguilar, "Efficacy of Sanitizers in Reducing Escherichia coli O157:H7, Salmonella spp. and Listeria monocytogenes Populations on FreshCut Carrots," Food Control, Vol. 18, No. 11, 2007, pp. 1383-1390. doi:10.1016/j.foodcont.2006.09.008

[13] Y. Han, D. M. Sherman, R. H. Linton, S. S. Nielson and P. E. Nelson, "The Effects of Washing and Chlorine Dioxide Gas on Survival and Attachment of Escherichia coli O157:H7 to Green Pepper Surfaces," Food Microbiology, Vol. 17, No. 5, 2000, pp. 521-533. 
doi:10.1006/fmic. 2000.0343

[14] A. Allende, J. McEvoy, Y. Tao and Y. Luo, "Antimicrobial Effect of Acidified Sodium Chlorite, Sodium Chlorite, Sodium Hypochlorite, and Citric Acid on Escherichia coli $\mathrm{O} 157: \mathrm{H} 7$ and Natural Microflora of Fresh-Cut Cilantro," Food Control, Vol. 20, No. 3, 2009, pp. 230234. doi:10.1016/j.foodcont.2008.05.009

[15] J. Bang, H. Kim, H. Kim, L. R. Beuchat and J. H. Ryu, "Combined Effects of Chlorine Dioxide, Drying, and Dry Heat Treatments in Inactivating Microorganisms on Radish Seeds," Food Microbiology, Vol. 28, No. 1, 2011, pp. 114-118. doi:10.1016/j.fm.2010.09.002

[16] S. Koide, D. Shitanda, M. Note and W. Cao, "Effects of Mildly Heated, Slightly Acidic Electrolyzed Water on the Disinfection and Physicochemical Properties of Sliced Carrot," Food Control, Vol. 22, No. 3-4, 2011, pp. 452456. doi:10.1016/j.foodcont.2010.09.025

[17] D. Xiao, R. Ye, M. Davidson, D. G. Hayes, D. A. Golden and Q. Zhong, "Sucrose Monolaurate Improves the Efficacy of Sodium Hypochlorite against Escherichia coli O157:H7 on Spinach," International Journal of Food Microbiology, Vol. 145, No. 1, 2011, pp. 64-68. doi:10.1016/j.ijfoodmicro.2010.11.029

[18] R. C. Soliva-Fortuny and O. Martin-belloso, "New Advances in Extending the Shelf-life of Fresh-cut Fruits: A Review," Trends in Food Science \& Technology, Vol. 14, No. 9, 2003, pp. 341-353. doi:10.1016/S0924-2244(03)00054-2

[19] D. F. Olivera, S. Z. Viña, C. M. Marani, R. M. Ferreyra, A. Mugridge, A. R. Chaves and R. H. Mascheroni, "Effect of Blanching on the Quality of Brussels Sprouts (Brassica oleracea L. gemmifera DC) after Frozen Storage," Journal of Food Engineering, Vol. 84, No. 1, 2008, pp. 148-155. doi:10.1016/j.jfoodeng.2007.05.005

[20] J. W. Heaton and A. G. Marangoni, "Chlorophyll Degradation in Processed Foods and Senescent Plant Tissues," Trends in Food Science and Technology, Vol. 7, No. 1, 1996, pp. 8-15. doi:10.1016/0924-2244(96)81352-5

[21] P. M. A. Toivonen and D.A. Brummell, "Biochemical Bases of Appearance and Texture Changes in Fresh-Cut Fruit and Vegetable," Postharvest Biology and Technology,
Vol. 48, No. 1, 2008, pp. 1-14. doi:10.1016/i.postharvbio.2007.09.004

[22] E. Lešková, J. Kubíková, E. Kováčiková, M. Košická, J. Porubská and K. Holčíková, "Review: Vitamin Losses: Retention during Heat Treatment and Continual Changes Expressed by Mathematical Models," Journal of Food Composition and Analysis, Vol. 19, No. 4, 2006, pp. 252276. doi:10.1016/j.jfca.2005.04.014

[23] P. Sungpuag, S. Tangchitpianvit, U. Chittchang and U. Wasantwisut, "Retinol and $\beta$-Carotene Content of Indigenous Raw and Home-Prepared Foods in Northeast Thailand," Food Chemistry, Vol. 64, No. 2, 1999, pp. 163167. doi:10.1016/S0308-8146(98)00154-X

[24] A. W. Munyaka, I. Oey, A. V. Loey and M. Hendrickx, "Analytical Methods: Application of Thermal Inactivation of Enzymes during Vitamin C Analysis to Study the Influence of Acidification, Crushing and Blanching on Vitamin C Stability in Broccoli (Brassica oleracea L var. italica)," Food Chemistry, Vol. 120, No. 2, 2010, pp. 591-598. doi:10.1016/j.foodchem.2009.10.029

[25] G. A. Francis and D. O'Beirne, "Effects of Vegetable Type and Antimicrobial Dipping on Survival and Growth of Listeria innocua and Escherichia coli," International Journal of Food Science \& Technology, Vol. 37, No. 6, 2002, pp. 711-718. doi:10.1046/j.1365-2621.2002.00622.x

[26] A. E. Watada and L. Qi, "Quality of Fresh-Cut Produce," Postharvest Biology and Technology, Vol. 15, No. 3, 1999, pp. 201-205. doi:10.1016/S0925-5214(98)00085-4

[27] K. W. Soli, A. Motomatsu, A. Yoshizumi, M. Yamakawa, T. Mishima, K, Honjoh and T. Miyamoto, "Comparison of the Bactericidal Effect of Slightly Acidic Hypochlorous Water with that of Conventional Sterilizers," Journal of Faculty of Agriculture, Vol. 55, No. 2, 2010, pp. 275 280.

[28] D. Rico, A. B. Martin-Diana, J. M. Barat and C. BarryRyan, "Extending and Measuring the Quality of Fresh-Cut Fruit and Vegetables: A Review," Trends in Food Science \& Technology, Vol. 18, No. 7, 2007, pp. 373-386. doi:10.1016/i.tifs.2007.03.011 